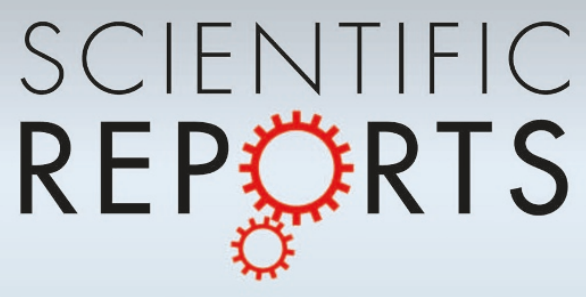

OPEN

SUBJECT AREAS:

BATTERIES

MECHANICAL PROPERTIES

ELECTRICAL AND ELECTRONIC ENGINEERING

Received

14 November 2013

Accepted

18 February 2014

Published

2 April 2014

Correspondence and requests for materials should be addressed to

D.Y.W.Y. (denisyu@

cityu.edu.hk) or S.K.B. (batabyal@ntu.edu.sg)

\section{Bulk antimony sulfide with excellent cycle stability as next-generation anode for lithium-ion batteries}

\author{
Denis Y. W. Yu ${ }^{1,2,3}$, Harry E. Hoster ${ }^{2} \&$ Sudip K. Batabyal ${ }^{3}$
}

\begin{abstract}
'School of Energy and Environment, City University of Hong Kong, Tat Chee Avenue, Kowloon, Hong Kong SAR, ${ }^{2}$ TUM CREATE, \# 10-02 CREATE Tower, Singapore 138602, Singapore, ${ }^{3}$ Energy Research Institute @ NTU, Nanyang Technological University, 50 Nanyang Avenue, Singapore 639798, Singapore.
\end{abstract}

Nanomaterials as anode for lithium-ion batteries (LIB) have gained widespread interest in the research community. However, scaling up and processibility are bottlenecks to further commercialization of these materials. Here, we report that bulk antimony sulfide with a size of 10-20 $\mu \mathrm{m}$ exhibits a high capacity and stable cycling of $800 \mathrm{mAh} \mathrm{g}^{-1}$. Mechanical and chemical stabilities of the electrodes are ensured by an optimal electrode-electrolyte system design, with a polyimide-based binder together with fluoroethylene carbonate in the electrolyte. The polyimide binder accommodates the volume expansion during alloying process and fluoroethylene carbonate suppresses the increase in charge transfer resistance of the electrodes. We observed that particle size is not a major factor affecting the charge-discharge capacities, rate capability and stability of the material. Despite the large particle size, bulk antimony sulfide shows excellent rate performance with a capacity of $580 \mathrm{mAh} \mathrm{g}^{-1}$ at a rate of $2000 \mathrm{~mA} \mathrm{~g}^{-1}$.

ithium-ion batteries (LIB) have been in the market for more than 20 years. They are now ubiquitous and can be found in numerous applications ranging from cell phones, laptop, power tools and electric vehicles. Even though many engineering advances have been made to a cell to enhance its energy density and stability, the basic materials in commercial cell remain almost the same as 20 years ago. In particular, graphite is still the primary material used as anode in LIB. Theoretical capacity of graphite is $370 \mathrm{mAhg}^{-1}$, and practical capacity close to that value is routinely obtained in commercial cells. To increase the energy density further, new materials have to be developed. Elements such as $\mathrm{Sn}$ and $\mathrm{Si}^{1-3}$, metal oxide materials such as $\mathrm{SnO}_{2}, \mathrm{SiO}_{2} \mathrm{Fe}_{2} \mathrm{O}_{3}{ }^{4}$, and metal sulfides such as $\mathrm{Cu}_{\mathrm{x}} \mathrm{S}, \mathrm{Ni}_{\mathrm{x}} \mathrm{S}, \mathrm{SnS}_{2}, \mathrm{MoS}_{2}, \mathrm{Sb}_{2} \mathrm{~S}_{3}$, etc. ${ }^{5-12}$ have been investigated as potential candidates for new generation anode materials. These materials undergo conversions reaction and/or alloying with $\mathrm{Li}$, resulting in a capacity of $>500 \mathrm{mAhg}^{-14}$. However, poor cycling stability has prevented their immediate commercialization. Much work has been conducted to improve cycle stability by nano-sizing the materials. Yet, large-scale synthesis and processibility of nano-materials remain a challenge. The purpose of this study is to identify the major factors affecting the stability of the new anode materials and to find out if it is possible to stabilize their bulk counterparts by different electrode formulations. This will bring greater technological impact to battery applications.

In this article, our focus is on alloy-based metal sulfide $\left(M_{x} S\right)$ as anode materials because they can undergo both conversion reaction between $\mathrm{Li}$ and $\mathrm{M}_{\mathrm{x}} \mathrm{S}$ and alloying reaction of the remaining metal with $\mathrm{Li}$, resulting in higher charge and discharge capacities. Capacity degradation observed in these materials is typically attributed to large volume expansion/contraction during charge and discharge, and also dissolution of polysulfide from the active material. However, very few studies attempted to isolate the mechanical and chemical influences on the stability of the electrode. In particular, most of the research work on metal sulfides focused only on the synthesis and application of nano-sizes, nanomorphologies and graphene-based composites to suppress the volume expansion $^{13-16}$. Here we want to identify and overcome the challenges when bulk materials are used. In this study, we have shown that particle size is in fact not the most crucial factor on the stability of the active materials. We achieved excellent cycle performance and rate capability using bulk materials by ensuring the mechanical and chemical stabilities of the electrodes. To understand the mechanical and chemical stabilities of the electrode, the effects of binder and electrolyte additive on the cycle performance of the metal sulfide electrodes were analysed systematically. Antimony sulfide $\left(\mathrm{Sb}_{2} \mathrm{~S}_{3}\right)$ is chosen as the model system for this work because it is commercially available and can also be synthesized easily. $\mathrm{Sb}_{2} \mathrm{~S}_{3}$ also has a working potential of around $1 \mathrm{~V} \mathrm{vs}$. $\mathrm{Li} / \mathrm{Li}^{+}$, far away from the potential of $\mathrm{Li}$ dendrite formation, making it a safer anode material for fast charging applications. 
Different factors affecting the electrochemical performance of the $\mathrm{Sb}_{2} \mathrm{~S}_{3}$ electrode are identified and the issues are resolved by using a proper electrode-electrolyte system. These results can be equally applicable to other metal sulfides materials such as $\mathrm{SnS}$ and $\operatorname{In}_{2} \mathrm{~S}_{3}$, etc.

Theoretically, $\mathrm{Sb}_{2} \mathrm{~S}_{3}$ can undergo both conversion reaction and alloy formation, as described by Equation 1 and 2 .

$$
\text { Conversion : } 1 / 2 \mathrm{Sb}_{2} \mathrm{~S}_{3}+3 \mathrm{Li}^{+}+3 \mathrm{e}^{-} \rightarrow \mathrm{Sb}+3 / 2 \mathrm{Li}_{2} \mathrm{~S}
$$

Conversion + alloying : $1 / 2 \mathrm{Sb}_{2} \mathrm{~S}_{3}+6 \mathrm{Li}^{+}+6 \mathrm{e}^{-} \rightarrow \mathrm{Li}_{3} \mathrm{Sb}+3 / 2 \mathrm{Li}_{2} \mathrm{~S}(2)$

Theoretical capacity for the conversion reaction is $473 \mathrm{mAh} \mathrm{g}^{-1}(3$ electrons transfer per mole of $\mathrm{Sb}$ ) where as that for full reaction is $946 \mathrm{mAh} \mathrm{g}^{-1}$ (6 electrons transfer). Electrodes with polyvinylidene fluoride (PVdF), carboxymethyl cellulose sodium salt (CMC) or polyimide binder were compared to understand the mechanical influence on electrode stability. Systematic analyses were carried out to isolate the contribution from volume change, surface reaction and polysulfide dissolution in each of these cases. At the end of the paper, the effect of particle size on capacity and rate performance was assessed using the optimal cell configuration.

\section{Results}

Physical characterization. Before electrochemical evaluation, the crystal structure of the materials was investigated by $\mathrm{X}$-ray diffraction (XRD). Both bulk crystalline $\mathrm{Sb}_{2} \mathrm{~S}_{3}$ and the $\mathrm{Sb}_{2} \mathrm{~S}_{3}$ wire show an orthorhombic structure with a Pbnm space group (see Figure 1a), as reported in literature ${ }^{9,14,17}$. All the peaks match well with that of $\mathrm{Sb}_{2} \mathrm{~S}_{3}$ (ICDD 00-042-1393).

The morphologies of the materials were characterized by scanning electron microscopy (SEM). SEM images of the materials are shown in Figure 1. Bulk crystalline $\mathrm{Sb}_{2} \mathrm{~S}_{3}$ from Sigma Adrich had a particle size ranging from $10-20 \mu \mathrm{m}$ (Figure $1 \mathrm{~b}$ ). In contrast, the $\mathrm{Sb}_{2} \mathrm{~S}_{3}$ wire obtained from hydrothermal synthesis showed a width of about $1 \mu \mathrm{m}$ and a length of about $10 \mu \mathrm{m}$ (Figure 1c).
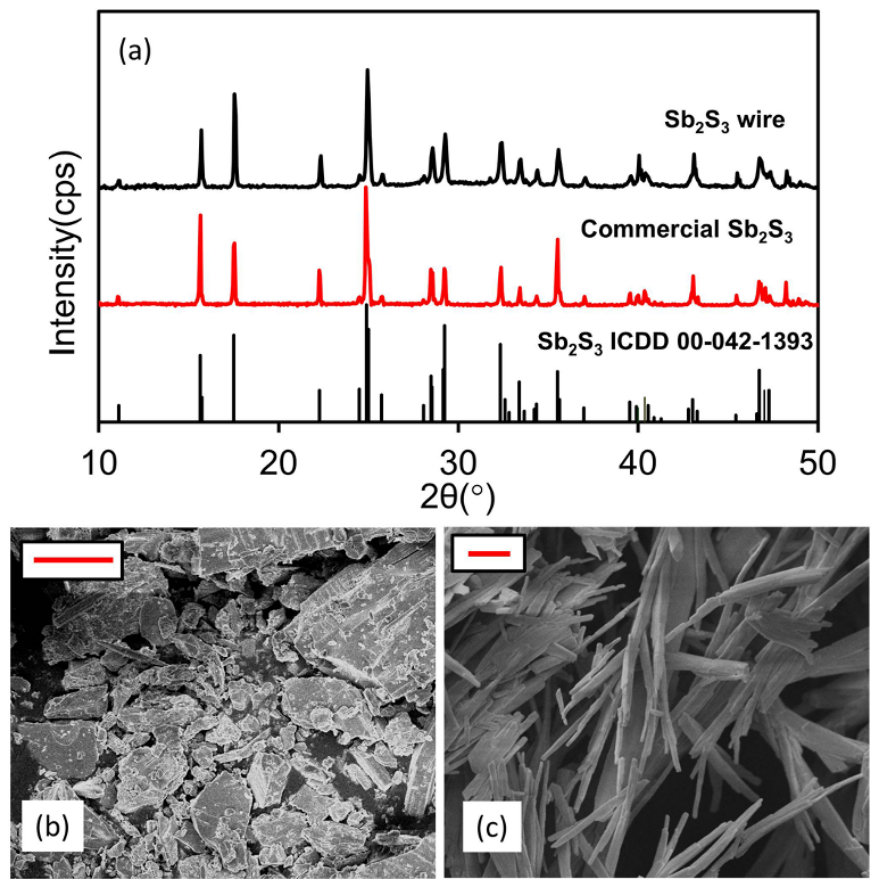

Figure 1 Structure and morphology of $\mathrm{Sb}_{2} \mathrm{~S}_{3}$ samples. (a) XRD of bulk $\mathrm{Sb}_{2} \mathrm{~S}_{3}$ and synthesized $\mathrm{Sb}_{2} \mathrm{~S}_{3}$ wires; (b) SEM images of bulk $\mathrm{Sb}_{2} \mathrm{~S}_{3}$ (scale bar: $10 \mu \mathrm{m}$ ) and (c) $\mathrm{Sb}_{2} \mathrm{~S}_{3}$ wires (scale bar: $2 \mu \mathrm{m}$ ).
Mechanical and chemical contributions to cycle stability. Initial electrochemical evaluation of bulk $\mathrm{Sb}_{2} \mathrm{~S}_{3}$ was carried out with $20 \mathrm{wt} \%$ $\mathrm{PVdF}$ as the binder in EC/DEC electrolyte. The constant current charge-discharge profiles are shown in Figure 2a. During first discharge, 2 plateaus were observed. The plateau at around $1.4 \mathrm{~V}$ is attributed to the conversion reaction of $\mathrm{Sb}_{2} \mathrm{~S}_{3}$ to $\mathrm{Li}_{2} \mathrm{~S}$ and $\mathrm{Sb}^{9}$. The lower plateau at around $0.8 \mathrm{~V}$ was due to alloying of $\mathrm{Sb}$ with $\mathrm{Li}^{18}$. In terms of capacity, $473 \mathrm{mAh} \mathrm{g}^{-1}$ and $938 \mathrm{mAh} \mathrm{g}^{-1}$ can be obtained from the material during first discharge to $1 \mathrm{~V}$ and $0 \mathrm{~V}$, respectively. This corresponds to a transfer of about 3 electrons and 6 electrons, which is consistent with the theoretical reactions as stated in Equation 1 and 2. The formation of metallic $\mathrm{Sb}$ was supported by ex-situ XRD study of $\mathrm{Sb}_{2} \mathrm{~S}_{3}$ when discharged to $1.0 \mathrm{~V}$ (See Supplementary Figure S1 for details). With further lithiation, the $\mathrm{Sb}$ peaks decreased in intensity, suggesting there was reaction between $\mathrm{Sb}$ and $\mathrm{Li}$ at lower voltage. Though, no crystalline phases could be seen at the end of discharge (to $0 \mathrm{~V}$ ), either because $\mathrm{Li}_{2} \mathrm{~S}$ and $\mathrm{Li}_{3} \mathrm{Sb}$ formed were amorphous, or too small to be detected by XRD. The result suggested that bulk $\mathrm{Sb}_{2} \mathrm{~S}_{3}$ can undergo full conversion and alloying during first discharge. However, limitation in capacity was observed during charging: only a charge capacity of $436 \mathrm{mAh} \mathrm{g}^{-1}$ can be obtained when charged to $2.5 \mathrm{~V}$ vs. $\mathrm{Li} / \mathrm{Li}^{+}$, corresponding to a cycle efficiency of $46.4 \%$. Less than half of the Li can be extracted from the $\mathrm{Sb}_{2} \mathrm{~S}_{3}$ electrode with PVdF during the charging step. We will show in a later section that the charge capacity is highly affected by the type of binder.

The cycle performance of the $\mathrm{Sb}_{2} \mathrm{~S}_{3}$ electrode with $20 \% \mathrm{PVdF}$ is shown in Figure 2b. When the electrode was cycled between 0 and $2.5 \mathrm{~V}$ vs. $\mathrm{Li} / \mathrm{Li}^{+}$with EC/DEC electrolyte, significant capacity fading was observed, with a loss of more than $50 \%$ after 50 cycles at $250 \mathrm{~mA}$ $\mathrm{g}^{-1}$. Three typical reasons were often cited for the capacity fading of metal sulfide materials: volume change, surface degradation and
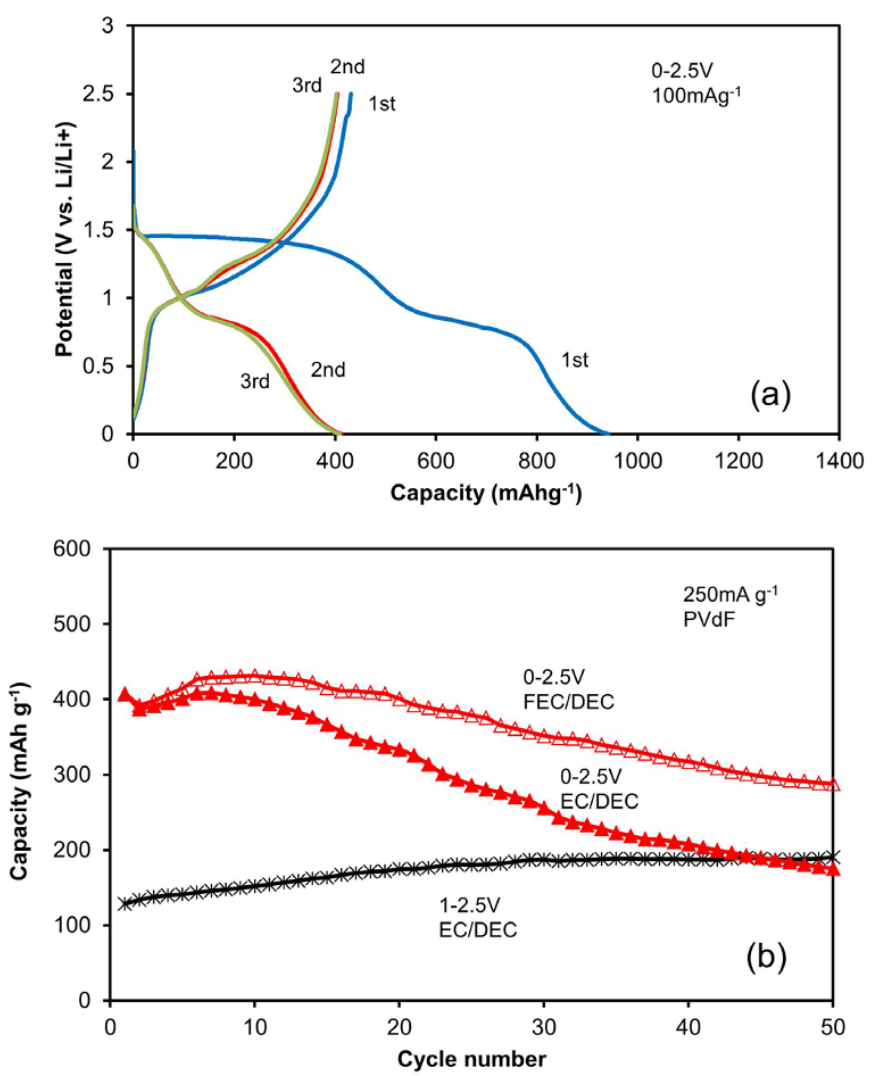

Figure $2 \mid$ Electrochemical performance of bulk $\mathrm{Sb}_{2} \mathrm{~S}_{3}$ with PVdF binder. (a) Charge-discharge profiles of bulk $\mathrm{Sb}_{2} \mathrm{~S}_{3}$ with PVdF binder. (b) Cycle performance of bulk $\mathrm{Sb}_{2} \mathrm{~S}_{3}$ with PVdF binder at $250 \mathrm{mAg}^{-1}$. 
polysulfide dissolution, as shown in a schematic in Figure 3. Here, we analyzed the contribution from each factor separately by isolating their effect. This can be achieved by carefully varying the test conditions and materials. We noticed in Equation 1 and 2 that volume change from alloying mechanism only occurs below $1 \mathrm{~V}$. So it is possible to avoid this contribution by limiting the test voltage range above $1 \mathrm{~V}$ vs. $\mathrm{Li} / \mathrm{Li}^{+}$(between 1 and $2.5 \mathrm{~V}$ in our experiment). The electrode showed a stable capacity even with PVdF binder in EC/ DEC electrolyte when cycled in a higher potential range (see Figure 2b).

Since only conversion reaction with the formation of $\mathrm{Li}_{\mathrm{x}} \mathrm{S}$ occurs between 1 and $2.5 \mathrm{~V}$, the result has two implications: first, polysulfide dissolution is not a major contribution to cycle degradation, at least not within the first 50 cycles because the capacity was stable despite $\mathrm{Li}_{\mathrm{X}} \mathrm{S}$ formation; second, the difference between the cycle performance of $0-2.5 \mathrm{~V}$ (capacity fading) and $1-2.5 \mathrm{~V}$ (stable capacity) is due to the utilization of the electrode below $1 \mathrm{~V}$, from the reaction between $\mathrm{Sb}$ and $\mathrm{Li}$. Therefore, the alloying reaction between $\mathrm{Sb}$ and $\mathrm{Li}$ causes much of the capacity fading in the electrode.

There are two main contributions to the capacity fading from the alloying reaction: surface reaction between the electrolyte and the active material (chemical effect) and volume expansion/contract of the particles during charge-discharge (mechanical effect). We investigated the contribution from the surface effect of the same $\mathrm{Sb}_{2} \mathrm{~S}_{3}$ electrodes with PVdF binder by using different electrolytes. Several research groups had reported that the solid electrolyte interphase (SEI) of alloy materials such as $\mathrm{Si}$ and $\mathrm{Sb}$ anode can be strengthened by the use of fluorinated ethylene carbonate (FEC) as an additive in the electrolyte ${ }^{19-23}$. We expect FEC will have similar effect for the alloying process in $\mathrm{Sb}_{2} \mathrm{~S}_{3}$. $\mathrm{Sb}_{2} \mathrm{~S}_{3}$ electrodes with $\mathrm{PVdF}$ were tested with $1 \mathrm{M} \mathrm{LiPF}_{6}$ in FEC/DEC $=1: 1$ between 0 and $2.5 \mathrm{~V}$, and the result is shown in Figure $2 \mathrm{~b}$. Capacity retention after 50 cycles was improved from $42.9 \%$ with EC/DEC to $66.7 \%$ with FEC/DEC. Since the only difference in the battery is the electrolyte, the $23.8 \%$ increase in capacity retention with FEC/DEC indicates that surface reaction is also a major factor in the cycle stability of the anode material. Further investigation of the effect of FEC on impedance of the electrode will be discussed in a later section. Even with FEC/DEC as the electrolyte, there remained a $30 \%$ drop in capacity after 50 cycles using PVdF as the binder, which suggests that there is still a large contribution from the volume change on the cycle stability of the electrode.

Effect of binder. Since our initial results indicated that volume change has a big effect on electrode stability, it is reasonable to see if it is possible to keep the structural integrity of the electrode by changing the binder. A flexible binder that can withstand large strain would be preferred. Instead of PVdF, which is a common electrode binder, electrodes with bulk $\mathrm{Sb}_{2} \mathrm{~S}_{3}$ were made with $\mathrm{CMC}$ and polyimide binder (DB100) - CMC and polyimide binder have been demonstrated to show improved cycle performance in alloy anodes such as $\mathrm{Sn}, \mathrm{Si}$ and $\mathrm{SiO}^{24-30}$. All the electrodes were made with $20 \mathrm{wt} \%$ acetylene black $(\mathrm{AB})$ and $20 \mathrm{wt} \%$ binder and tested under the same conditions as described before. Because of the large amount of acetylene black and binder, reference electrodes were also made with Cu powder (Alfa Aesar 350 mesh 8-11 $\mu \mathrm{m}$ ) in the same

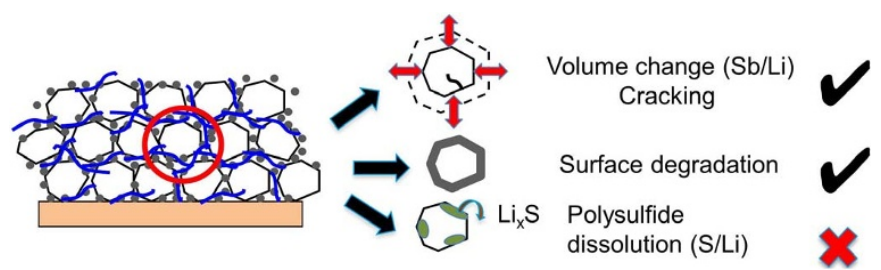

Figure $3 \mid$ Schematic diagram of the typical causes of capacity fading in metal sulfide electrodes. ratio of $\mathrm{Cu}: \mathrm{AB}$ :binder $=6: 2: 2$ to determine the contribution from the carbon and binder. Since $\mathrm{Cu}$ does not alloy with $\mathrm{Li}$, the capacities from these reference electrodes reflect the $\mathrm{Li}$ accommodation in the carbon black and the binder. The specific capacities reported in this study for these reference electrodes were calculated with respect to the mass of $\mathrm{Cu}$. Even though strictly speaking Li were not inserted into $\mathrm{Cu}$ but the carbon black and binder in the electrode, this allows direct comparison with the capacity of $\mathrm{Sb}_{2} \mathrm{~S}_{3}$ electrodes because the electrode composition of $6: 2: 2$ was the same.

Cyclic voltammetry of electrodes with PVdF, CMC and DB100 were tested and the first cycle and second cycle voltammograms are shown in Figure $4 \mathrm{a}$ and $4 \mathrm{~b}$. All three sets of electrodes with different binders show reduction reactions around $1.18 \mathrm{~V}$ and $0.76 \mathrm{~V}$ and oxidation reaction at $1.10 \mathrm{~V}$ during first cycle, which are typical of the conversion and alloying processes in Equation 1 and 2. There was not much difference between the peak intensities of electrodes with PVdF and CMC, indicating similar capacities from the electrode with these two binders. This was confirmed by constant-current tests at $100 \mathrm{~mA} \mathrm{~g}^{-1}$ where a charge capacity of about $450 \mathrm{mAh} \mathrm{g}^{-1}$ was obtained after first cycle for both electrodes (see Supplemenary Table S1). Electrodes with DB100, on the other hand, show much higher reaction currents, especially below $1 \mathrm{~V}$ in the $\mathrm{CV}$ profiles (Figure $4 \mathrm{a}$ and $4 \mathrm{~b}$ ). Some of the contributions in current originates from the polyimide binder, which was evident from the reference electrode with $\mathrm{Cu}: \mathrm{AB}: \mathrm{DB} 100$. Still, a large difference in intensity was observed during the second cycle with DB100 binder, indicating an enhanced electrochemical performance of $\mathrm{Sb}_{2} \mathrm{~S}_{3}$ with the polyimide binder.

Constant-current charge-discharge tests were then carried out and the profiles are shown in Figure 5. The contributions from carbon black and binders can be first estimated from the $\mathrm{Cu}$ reference electrodes. First discharge capacities of Cu:AB:binder were 183.9, 129.9
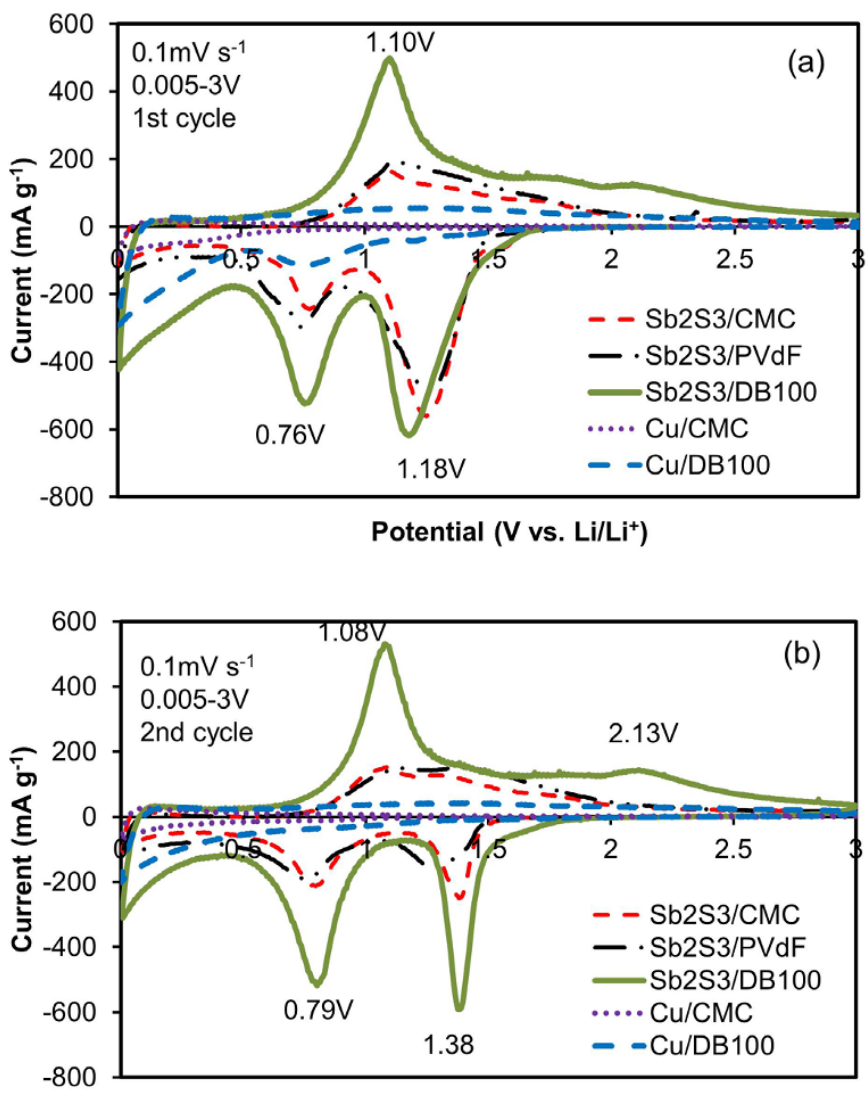

Potential (V vs. Li/Li+)

Figure 4 Cyclic voltammograms of bulk $\mathrm{Sb}_{2} \mathrm{~S}_{3}$ and $\mathrm{Cu}$ with different binders at a scan rate of $0.1 \mathrm{mV} \mathrm{s}^{-1}$. (a) $1^{\text {st }}$ cycle; (b) $2^{\text {nd }}$ cycle. 

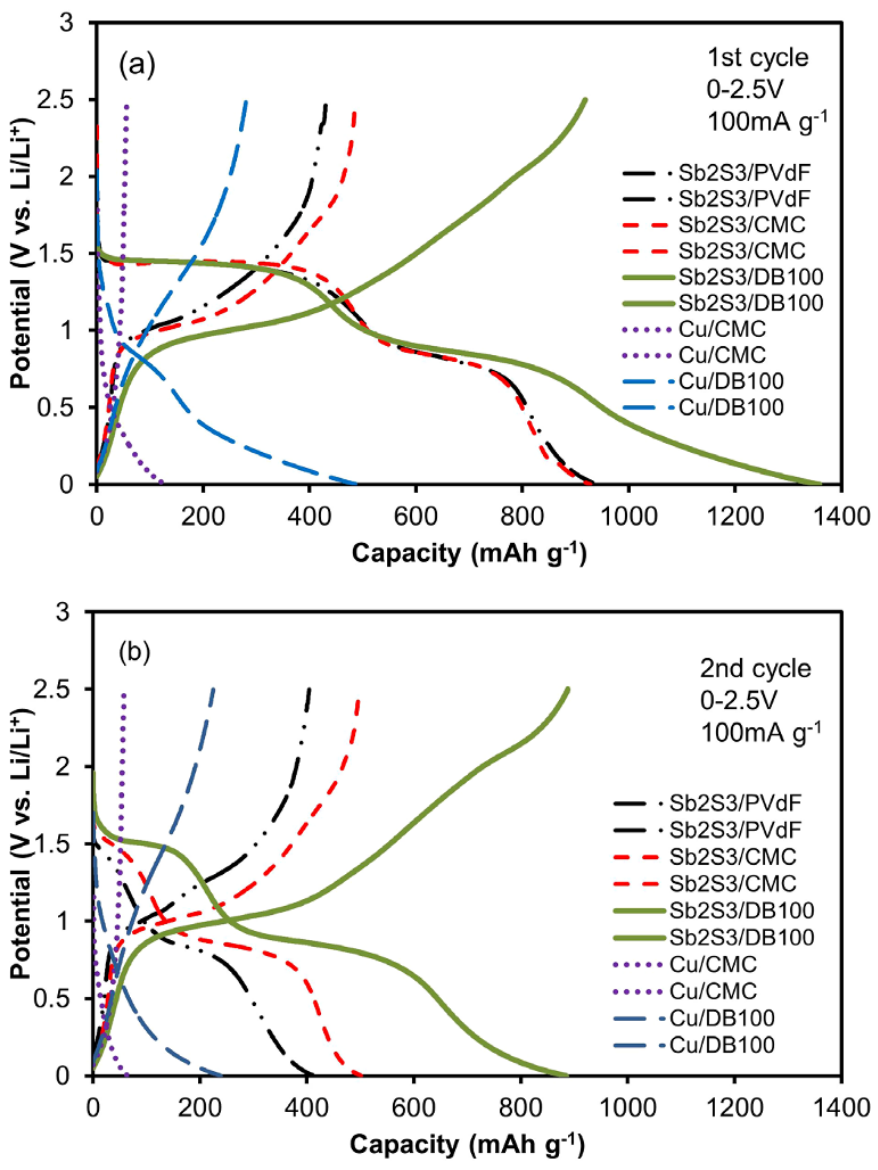

Figure 5 | Charge-discharge profiles of bulk $\mathrm{Sb}_{2} \mathrm{~S}_{3}$ and $\mathrm{Cu}$ with different binders at a current rate of $100 \mathrm{~mA} \mathrm{~g}^{-1}$. (a) $1^{\text {st }}$ cycle; (b) $2^{\text {nd }}$ cycle.

and $488.0 \mathrm{mAh}^{-1}$ for PVdF, CMC and DB100, respectively. Conversely, first charge capacities were only 78.3, 56.2 and $280.6 \mathrm{mAh} \mathrm{g}^{-1}$ for the electrodes with the three binders. Only a small amount of capacity was obtained from reference electrodes with PVdF and CMC. DB100, on the other hand, shows some degree of Li uptake and removal.

After systematic analyzing the effect from $\mathrm{AB}$ and binder, the results from the $\mathrm{Sb}_{2} \mathrm{~S}_{3}$ electrodes become clearer. $\mathrm{Sb}_{2} \mathrm{~S}_{3}$ electrodes with $\mathrm{PVdF}$ and $\mathrm{CMC}$ showed a first discharge capacity of around $930 \mathrm{mAh} \mathrm{g}^{-1}$, out of which $\mathrm{AB}$ and binder accounts for about 130$180 \mathrm{mAh} \mathrm{g}^{-1}$. (See Supplementary Table S1) So the actual amount of capacity uptake by $\mathrm{Sb}_{2} \mathrm{~S}_{3}$ material was about $750-800 \mathrm{mAh} \mathrm{g}^{-1}$. On the other hand, $\mathrm{Sb}_{2} \mathrm{~S}_{3}$ electrode with DB100 showed a first discharge capacity of $1358.5 \mathrm{mAh} \mathrm{g}^{-1}$, which was above the theoretical capacity of $\mathrm{Sb}_{2} \mathrm{~S}_{3}$. This was in fact reasonable because $488.0 \mathrm{mAh} \mathrm{g}^{-1}$ of the electrode capacity originates from $\mathrm{AB}$ and $\mathrm{DB} 100$. Figure $5 \mathrm{a}$ also shows that the main difference between the discharge curves of $\mathrm{Sb}_{2} \mathrm{~S}_{3}$ electrode with CMC and DB100 was the increase in capacity below $1 \mathrm{~V}$, which is due to the $\mathrm{Li}$ accommodation in the polyimide binder. During charging, a much higher capacity could be obtained from $\mathrm{Sb}_{2} \mathrm{~S}_{3}$ electrode with DB100 than those with PVdF and CMC. The increase in capacity by changing binder in the $\mathrm{Sb}_{2} \mathrm{~S}_{3}$ electrode from CMC to DB100 was about $430 \mathrm{mAh} \mathrm{g}^{-1}$, which was higher than the amount of $\mathrm{Li}$ that can be removed from the polyimide binder. Thus, polyimide binder also enhanced the charge-discharge performance of the $\mathrm{Sb}_{2} \mathrm{~S}_{3}$ material in the electrode. This was evident in the second charge profile in Figure $5 \mathrm{~b}$ - increased capacity from the $\mathrm{Sb}_{2} \mathrm{~S}_{3}$ electrode with DB100 was observed at both the $1 \mathrm{~V}$ plateau (alloying reaction) as well as around $2 \mathrm{~V}$ (conversion reaction). The

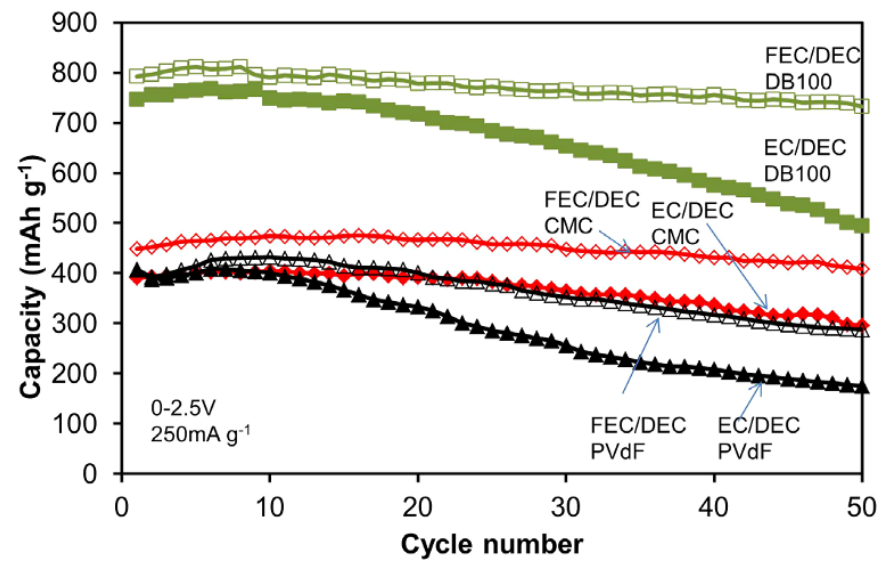

Figure 6 | Cycle performance of bulk $\mathrm{Sb}_{2} \mathrm{~S}_{3}$ with different binders at $250 \mathrm{mAg}^{-1}$. Solid - cells with EC/DEC; open - cells with FEC/DEC.

higher utilization of $\mathrm{Sb}_{2} \mathrm{~S}_{3}$ with $\mathrm{DB} 100$ binder was probably due to better binding of the particles within the electrode.

The three types of electrodes were then subjected to cycling at $250 \mathrm{~mA} \mathrm{~g}{ }^{-1}$ between 0 and $2.5 \mathrm{~V}$ with EC/DEC electrolyte. Lines with solid markers in Figure 6 correspond to the cells tested in EC/ DEC. Electrodes with PVdF or CMC start with similar initial capacity of about $400 \mathrm{mAh} \mathrm{g}^{-1}$, but the capacity retention after 50 cycles was higher with CMC binder, which clearly indicate the importance of binder in the cycle performance. On the other hand, electrode with DB100 gave an initial capacity of $750 \mathrm{mAh} \mathrm{g}^{-1}$, but capacity faded after cycling. By changing the electrolyte to FEC/DEC, cycle stability of all the electrodes were improved (lines with open markers in Figure 6). In particularly, the capacity retention after 50 cycles for the electrode with polyimide binder improved from $66.2 \%$ to $92.5 \%$ with FEC/DEC. This indicates that the use of FEC can effectively suppress capacity fading due to surface effect from the electrode with DB100. Our results showed that by changing the binder and electrolyte composition, high capacity with good stability can be obtained. Further work is in progress to clarify the origin of the remaining capacity loss, which can be due to the capacity loss from Li reaction with the polyimide binder and/or a small amount of polysulfide dissolution from the electrode during cycling.

The charge-discharge profiles of bulk $\mathrm{Sb}_{2} \mathrm{~S}_{3}$ with DB100 binder tested in EC/DEC and FEC/DEC are shown in Supplementary Figure S2. The decrease in capacity for both the conversion and alloying reactions (both $1.4 \mathrm{~V}$ and $0.8 \mathrm{~V}$ plateaus) can be suppressed by the use of FEC. In order to further understand the role of FEC electrolyte, impedance measurements at different cycle number were carried out with $10 \mathrm{mV}$ amplitude between $500 \mathrm{kHz}$ and $5 \mathrm{mHz}$. The cells were first discharged partially to $1.0 \mathrm{~V}$ and held at $1.0 \mathrm{~V}$ for 2 hours before impedance measurement. Figure 7 shows the Nyquist plots of the cell with EC/DEC and FEC/DEC after $5^{\text {th }}$ and $50^{\text {th }}$ cycles. After 5 cycles, both electrodes with EC/DEC and FEC/DEC showed similar chargetransfer resistance (solid lines in Figure 7). After 50 cycles, chargetransfer resistance for the cell tested with FEC/DEC remains the same. On the other hand, the cell tested with EC/DEC showed large increase in impedance. Our result indicated that the use of FEC suppresses the increase in surface resistance of the electrode, leading to better cycle stability.

Effect of particle size on electrochemical performance. In the previous section, we observed that bulk $\mathrm{Sb}_{2} \mathrm{~S}_{3}$ exhibited high capacity and good cycle stability with a suitable binder and electrolyte composition. Still one question remains: does reduction of particle size give additional benefit? To answer this, $\mathrm{Sb}_{2} \mathrm{~S}_{3}$ wires with a width of about $1 \mu \mathrm{m}$ were synthesized through a co-precipitation and hydrothermal process for comparison. Figure 1c shows the 


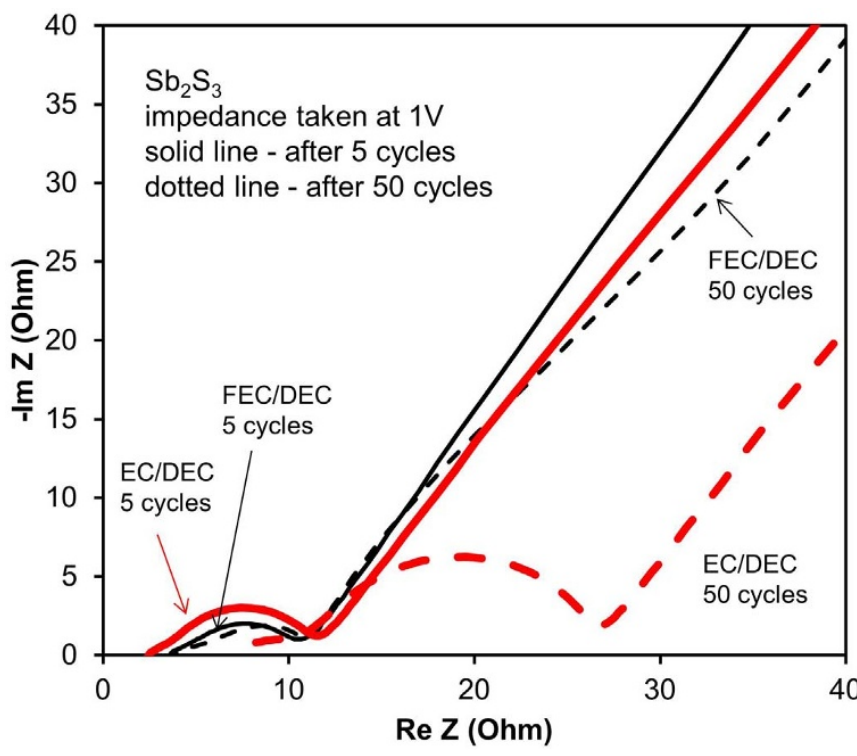

Figure 7 | Nyquist plots of $\mathrm{Sb}_{2} \mathrm{~S}_{3}$ half cells with DB100 binder. Electrode tested in EC/DEC (thick red line) and FEC/DEC (thin black line) electrolyte after $5^{\text {th }}$ and $50^{\text {th }}$ cycles.

morphology of the wires. The $\mathrm{Sb}_{2} \mathrm{~S}_{3}$ wires were made into electrodes with DB100 as the binder and tested with FEC/DEC electrolyte, the same as the one with bulk $\mathrm{Sb}_{2} \mathrm{~S}_{3}$.

Figure $8 \mathrm{a}$ shows the $2^{\text {nd }}$ cycle voltammograms of the $\mathrm{Sb}_{2} \mathrm{~S}_{3}$ wires and bulk $\mathrm{Sb}_{2} \mathrm{~S}_{3}$. Both electrodes showed similar charge-discharge peaks for alloying and conversion reactions of $\mathrm{Sb}_{2} \mathrm{~S}_{3}$. Electrode with $\mathrm{Sb}_{2} \mathrm{~S}_{3}$ wire showed additional peaks at 1.9 and $2.35 \mathrm{~V}$ during charging and $1.7 \mathrm{~V}$ during discharging. This may be due to trace amount of elemental $\mathrm{S}$ in the material. Other than the additional peaks in electrode with $\mathrm{Sb}_{2} \mathrm{~S}_{3}$ wire, both electrodes showed similar peak currents, indicating similar charge-discharge capacities. Constant-current tests of the electrodes were carried out and the cycle performance is shown in Figure $8 \mathrm{~b}$. $\mathrm{Sb}_{2} \mathrm{~S}_{3}$ wire showed slightly higher capacity than bulk $\mathrm{Sb}_{2} \mathrm{~S}_{3}$ at a rate of $250 \mathrm{~mA} \mathrm{~g}^{-1}$, but the difference is not significant.

Both electrodes gave good cycle performance because the polyimide binder provides mechanical stability to the electrodes and FEC suppresses surface reaction. The electrodes were also tested up to $2000 \mathrm{~mA} \mathrm{~g}^{-1}$ (see insert in Figure 8b). Surprisingly, the same rate performances were observed for both $\mathrm{Sb}_{2} \mathrm{~S}_{3}$ wire and bulk $\mathrm{Sb}_{2} \mathrm{~S}_{3}$. This indicates that no additional benefits were observed by reducing the particle size, and the reduction of particle size is not necessary for obtaining high rate and high capacity in these materials.

The charge-discharge profiles of bulk $\mathrm{Sb}_{2} \mathrm{~S}_{3}$ tested at different current rates are shown in Figure 8c. At a current rate of $2000 \mathrm{~mA}$ $\mathrm{g}^{-1}$, a charge capacity of $580 \mathrm{mAh} \mathrm{g}^{-1}$ could be obtained. This corresponds to a charge or discharge time of 17 minutes. This is significant because it is the highest rate capability ever reported for bulk 10$20 \mu \mathrm{m}$ materials. The ability to use bulk materials to get high capacity and high rate makes them one step closer to commercialization.

\section{Discussion}

Capacity and cycle performance of electrode materials are highly dependent on electrode configuration and electrolyte composition. Systematic investigations were carried out to analyse the factors affecting cycle performance. In the case of $\mathrm{Sb}_{2} \mathrm{~S}_{3}$, volume change and surface reactions were identified as the major factors affecting the electrode stability. Polysulfide dissolution is not a main factor for short-term stability (Figure 3 ). The use of polyimide binder allows higher utilization of the $\mathrm{Sb}_{2} \mathrm{~S}_{3}$ active material and provides good mechanical stability in the electrodes. In fact, some polyimide
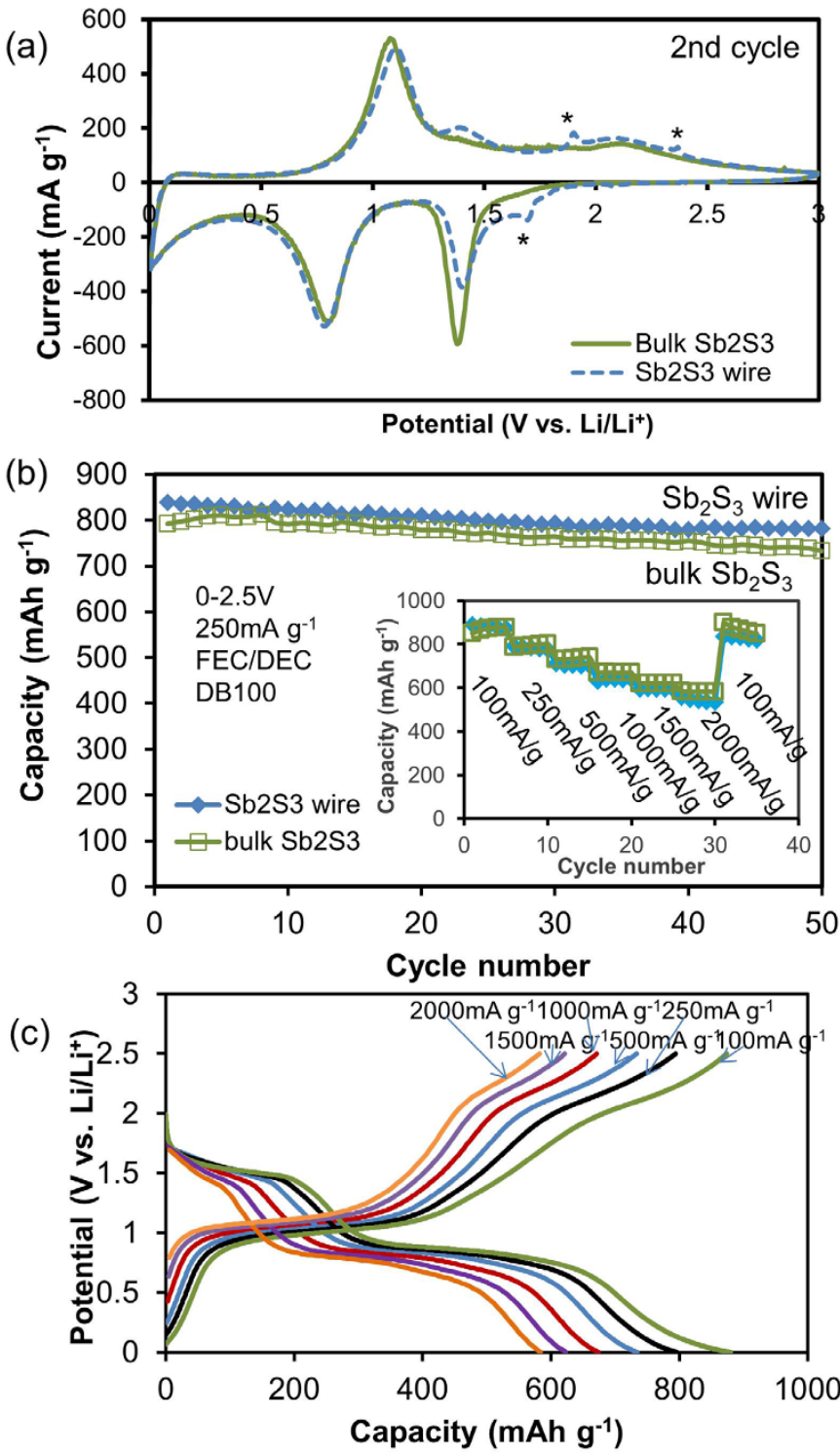

Figure 8 Comparison of $\mathrm{Sb}_{2} \mathrm{~S}_{3}$ wire and bulk $\mathrm{Sb}_{2} \mathrm{~S}_{3}$ with DB100 binder and FEC/DEC electrolyte. (a) $2^{\text {nd }}$ cycle voltammograms, (b) cycle and rate performance, $(c)$ charge-discharge profiles at different rates.

binders are active with $\mathrm{Li}$ and can lead to additional capacity in the electrode. Surface degradation and impedance change is suppressed by the use of FEC in the electrolyte. After judicial choosing the binder and electrolyte, electrodes with bulk $\mathrm{Sb}_{2} \mathrm{~S}_{3}$ gives a charge capacity of close to $800 \mathrm{mAh} \mathrm{g}^{-1}$ with stable cycle stability. Particle size effect is not found to be crucial once the electrode configuration and electrolyte is optimized. Nano-particles, which are difficult to handle and synthesize in large-scale, are not necessary to provide good electrochemical performances. Even electrodes with bulk $\mathrm{Sb}_{2} \mathrm{~S}_{3}$ can give up to $580 \mathrm{mAh} \mathrm{g}^{-1}$ at a rate of $2000 \mathrm{~mA} \mathrm{~g}^{-1}$, which is the highest ever recorded for materials with $10-20 \mu \mathrm{m}$ size.

\section{Methods}

Sample preparation and characterization. Two different types of $\mathrm{Sb}_{2} \mathrm{~S}_{3}$ samples were evaluated in this study: (1) Bulk crystalline $\mathrm{Sb}_{2} \mathrm{~S}_{3}$ was obtained from Sigma Aldrich and used as it is (denoted as " $\mathrm{Sb}_{2} \mathrm{~S}_{3}$ " in the paper). (2) Crystalline $\mathrm{Sb}_{2} \mathrm{~S}_{3}$ wire were made by an aqueous precipitation between $\mathrm{SbCl}_{3}$ in acetone and sodium thiosulfate $\left(\mathrm{Na}_{2} \mathrm{~S}_{2} \mathrm{O}_{3}\right)$ followed by a hydrothermal annealing at $150^{\circ} \mathrm{C}$ for 4 hours, adopted from procedure of $\mathrm{Li}$ et al. ${ }^{31}$.

Structure of the materials was studied by powder X-ray diffraction (XRD) with a $\mathrm{Cu}$ K_alpha (Bruker). Morphology and particle size of the tested materials were studied by field emission scanning electron microscope (SEM) with a JOEL JSM-7600F. 
Electrochemical evaluation. The $\mathrm{Sb}_{2} \mathrm{~S}_{3}$ active material was mixed with acetylene black (Alfa Aesar) and binder in a weight ratio of $6: 2: 2.20 \mathrm{wt} \%$ carbon was added to ensure sufficient electrical conductivity within the electrode. For binder, polyvinylidene fluoride (PVdF from Kynar HSV900), carboxymethyl cellulose sodium salt (CMC from Sigma Alrich) and polyimide binder (DB100 - Dreambond 100 from ISTUSA) were used. The materials were mixed in either 1-methyl-2 pyrrolidone (NMP) for PVdF and DB100 or de-ionized water for CMC to form a slurry. The slurry is then coated on roughened copper foil as a current collector using a doctor blade. The electrode was then dried at $80^{\circ} \mathrm{C}$ and compressed with a roll press. The electrodes were cut into $16 \mathrm{~mm}$ diameter discs and further dried at $110^{\circ} \mathrm{C}$ in vacuum for 4 hours before transferring into an Ar-filled glove box. An additional annealing step at $300^{\circ} \mathrm{C}$ for 5 hours in vacuum was performed on electrodes with DB100 to polymerize the binder before testing. Typical electrode thickness is between 20-30 $\mu \mathrm{m}$ with a packing density of about $1.0 \mathrm{~g} \mathrm{~cm}^{-3}$. The electrodes were assembled with Li metal as counter electrodes in a 2016 coin cell. $1 \mathrm{M}$ lithium

hexafluorophosphate $\left(\mathrm{LiPF}_{6}\right)$ in ethylene carbonate $(\mathrm{EC})$ to diethyl carbonate (DEC) of $1: 1$ is the typical electrolyte used in the cell. Electrolyte with fluoroethylene carbonate 4-fluoro-1,3-dioxolan-2-one (FEC) $\left(1 \mathrm{M} \mathrm{LiPF}_{6}\right.$ in FEC/DEC $\left.=1: 1\right)$ is also used to study how the stability of the electrodes with cycling can be improved chemically.

The cells were then tested with a battery tester between 0 to $2.5 \mathrm{~V} \mathrm{vs.} \mathrm{Li} / \mathrm{Li}^{+}$. Typical charge-discharge rate was $100 \mathrm{~mA} \mathrm{~g}^{-1}$ during the first five cycles and $250 \mathrm{~mA} \mathrm{~g}^{-1}$ in subsequent cycles. Cyclic voltammetry profiles were taken at a scan rate of $0.1 \mathrm{mVs}^{-1}$ between $0.005 \mathrm{~V}$ and $3 \mathrm{~V}$ vs. $\mathrm{Li} / \mathrm{Li}^{+}$. Impedance measurements were carried with a potentiostat (Biologic VMP3) between $500 \mathrm{kHz}$ and $5 \mathrm{mHz}$.

1. Huggins, R. A. Materials science principles related to alloys of potential use in rechargeable lithium cells. J. Power Sources 26, 109-120 (1989).

2. Yang, J., Wachtler, M., Winter, M. \& Besenhard, J. O. Sub-Microcrystalline Sn and $\mathrm{Sn}-\mathrm{SnSb}$ Powders as Lithium Storage Materials for Lithium-Ion Batteries. Electrochem. Solid-State Lett. 2, 161-163 (1999).

3. Kasavajjula, U., Wang, C. \& Appleby, A. J. Nano- and bulk-silicon-based insertion anodes for lithium-ion secondary cells. J. Power Sources 163, 1003-1039 (2007).

4. Cabana, J., Monconduit, L., Larcher, D. \& Palacín, M. R. Beyond IntercalationBased Li-Ion Batteries: The State of the Art and Challenges of Electrode Materials Reacting Through Conversion Reactions. Adv. Mater. 22, E170-E192 (2010)

5. Débart, A., Dupont, L., Patrice, R. \& Tarascon, J. M. Reactivity of transition metal ( $\mathrm{Co}, \mathrm{Ni}, \mathrm{Cu}$ ) sulphides versus lithium: The intriguing case of the copper sulphide. Solid State Sci. 8, 640-651 (2006).

6. Kim, T.-J., Kim, C., Son, D., Choi, M. \& Park, B. Novel $\mathrm{SnS}_{2}$-nanosheet anodes for lithium-ion batteries. J. Power Sources 167, 529-535 (2007).

7. Lai, C.-H. et al. Direct growth of high-rate capability and high capacity copper sulfide nanowire array cathodes for lithium-ion batteries. J. Mater. Chem. 20, 6638-6645 (2010)

8. Liu, J. \& Xue, D. Sn-based nanomaterials converted from $\mathrm{SnS}$ nanobelts: Facile synthesis, characterizations, optical properties and energy storage performances. Electrochim. Acta 56, 243-250 (2010).

9. Park, C.-M., Hwa, Y., Sung, N.-E. \& Sohn, H.-J. Stibnite $\left(\mathrm{Sb}_{2} \mathrm{~S}_{3}\right)$ and its amorphous composite as dual electrodes for rechargeable lithium batteries. J. Mater. Chem. 20, 1097-1102 (2010).

10. Hwang, H., Kim, H. \& Cho, J. $\mathrm{MoS}_{2}$ Nanoplates Consisting of Disordered Graphene-like Layers for High Rate Lithium Battery Anode Materials. Nano Lett. 11, 4826-4830 (2011).

11. Chang, K. et al. Few-layer $\mathrm{SnS}_{2} /$ graphene hybrid with exceptional electrochemical performance as lithium-ion battery anode. J. Power Sources 201, 259-266 (2012).

12. Lai, C.-H., Lu, M.-Y. \& Chen, L.-J. Metal sulfide nanostructures: synthesis, properties and applications in energy conversion and storage. J. Mater. Chem. 22, 19-30 (2012).

13. Yang, H., Su, X. \& Tang, A. Microwave synthesis of nanocrystalline $\mathrm{Sb}_{2} \mathrm{~S}_{3}$ and its electrochemical properties. Mater. Res. Bull. 42, 1357-1363 (2007).

14. Chen, L. et al. Preparation of rod-like $\mathrm{Sb}_{2} \mathrm{~S}_{3}$ dendrites processed in conventional hydrothermal. Mater. Lett. 63, 1258-1261 (2009).

15. Prikhodchenko, P. V. et al. Conversion of hydroperoxoantimonate coated graphenes to $\mathrm{Sb}_{2} \mathrm{~S}_{3} @$ graphene for a superior lithium battery anode. Chem. Mater. 24, 4750-4757 (2012).

16. Yu, D. Y. W. et al. High-capacity antimony sulphide nanoparticle-decorated graphene composite as anode for sodium-ion batteries. Nature Comm. 4, 2922 DOI: $10.1038 /$ ncomms3922 (2013).

17. Ma, J.et al. $\mathrm{Sb}_{2} \mathrm{~S}_{3}$ with Various Nanostructures: Controllable Synthesis, Formation Mechanism, and Electrochemical Performance toward Lithium Storage. Chem. a Eur. J. 16, 13210-13217 (2010)
18. Chen, W. X., Lee, J. Y. \& Liu, Z. The nanocomposites of carbon nanotube with Sb and $\mathrm{SnSb}_{0.5}$ as Li-ion battery anodes. Carbon 41, 959-966 (2003).

19. Dalavi, S., Guduru, P. \& Lucht, B. L. Performance Enhancing Electrolyte Additives for Lithium Ion Batteries with Silicon Anodes. J. Electrochem. Soc. 159, A642-A646 (2012)

20. Etacheri, V. et al. Effect of Fluoroethylene Carbonate (FEC) on the Performance and Surface Chemistry of Si-Nanowire Li-Ion Battery Anodes. Langmuir 28, 965-976 (2011).

21. Lin, Y.-M. et al. High performance silicon nanoparticle anode in fluoroethylene carbonate-based electrolyte for Li-ion batteries. Chem. Commun. 48, 7268-7270 (2012).

22. Wilhelm, H. A., Marino, C., Darwiche, A., Monconduit, L. \& Lestriez, B. Significant electrochemical performance improvement of TiSnSb as anode material for Li-ion batteries with composite electrode formulation and the use of VC and FEC electrolyte additives. Electrochem. Commun. 24, 89-92 (2012).

23. Nie, M., Abraham, D. P., Chen, Y., Bose, A. \& Lucht, B. L. Silicon Solid Electrolyte Interphase (SEI) of Lithium Ion Battery Characterized by Microscopy and Spectroscopy. J. Phys. Chem. C 117, 13403-13412 (2013).

24. Li, J., Lewis, R. B. \& Dahn, J. R. Sodium Carboxymethyl Cellulose: A Potential Binder for Si Negative Electrodes for Li-Ion Batteries. Electrochem. Solid-State Lett 10, A17-A20 (2007).

25. Lestriez, B., Bahri, S., Sandu, I., Roué, L. \& Guyomard, D. On the binding mechanism of CMC in Si negative electrodes for Li-ion batteries. Electrochem. Commun. 9, 2801-2806 (2007)

26. Ding, N. et al. Improvement of cyclability of $\mathrm{Si}$ as anode for $\mathrm{Li}$-ion batteries. J. Power Sources 192, 644-651 (2009).

27. Mazouzi, D., Lestriez, B., Roué, L. \& Guyomard, D. Silicon Composite Electrode with High Capacity and Long Cycle Life. Electrochem. Solid-State Lett. 12, A215-A218 (2009).

28. Guerfi, A. et al. SiOx-graphite as negative for high energy Li-ion batteries. J. Power Sources 196, 5667-5673 (2011)

29. Koo, B. et al. A Highly Cross-Linked Polymeric Binder for High-Performance Silicon Negative Electrodes in Lithium Ion Batteries. Ang. Chem. Inter. Ed 51, 8762-8767 (2012).

30. Kim, J. S. et al. Effect of polyimide binder on electrochemical characteristics of surface-modified silicon anode for lithium ion batteries. J. Power Sources 244, 521-526 (2013)

31. Li, C., Yang, X., Liu, Y., Zhao, Z. \& Qian, Y. Growth of crystalline $\mathrm{Sb}_{2} \mathrm{~S}_{3}$ nanorods by hydrothermal method. J. of Cryst. Growth 255, 342-347 (2003).

\section{Acknowledgments}

This study was supported by the National Research Foundation of Singapore under the TUM CREATE Centre for Electromobility and the Energy Research Institute at Nanyang Technological University, Singapore.

\section{Author contributions}

D.Y.W.Y. designed and carried out the electrochemical experiment and wrote the paper. H.E.H. supervised the work. S.K.B. performed material synthesis and characterization and co-wrote the paper.

\section{Additional information}

Supplementary information accompanies this paper at http://www.nature.com/ scientificreports

Competing financial interests: The authors declare no competing financial interests. How to cite this article: Yu, D.Y.W. \& Batabyal, S.K. Bulk antimony sulfide with excellent cycle stability as next-generation anode for lithium-ion batteries. Sci. Rep. 4, 4562. DOI:10.1038/srep04562 (2014).

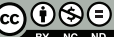

This work is licensed under a Creative Commons Attribution-NonCommercialNoDerivs 3.0 Unported License. The images in this article are included in the article's Creative Commons license, unless indicated otherwise in the image credit; if the image is not included under the Creative Commons license, users will need to obtain permission from the license holder in order to reproduce the image. To view a copy of this license, visit http://creativecommons.org/licenses/by-nc-nd/3.0/ 